\title{
Monitoring of Power Quality at Small Hydropower Plant - Case Study
}

\author{
Boris CFARKU ${ }^{1}$, Nako HOBDARI ${ }^{2}$ Astrit BARDHI ${ }^{3}$ \\ 1, 2, ${ }^{3}$ Polytechnic University of Tirana, Faculty of Electrical Enginering, “Sheshi Nënë Tereza”, Nr. 4, Albania
}

\begin{abstract}
In recent years, the interest of building small hydropower plants by operators working in the field of energy production in Albania is increased. These generations unit, which usually are connected at medium or low voltage line transmission of power system are built in all Albanian area and not coordinated with planning of distributed system. Due this reason, small hydropower plants in some cases have been caused some problem such as: overvoltage, overloaded of transmission line, switch off of power line etc. The capacities of transmission line are limited and often the new hydropower generations are forced to work with under their capacities. In this paper, we have presented the data of monitoring of a small hydropower station and analyzed them in order to find the rea sons that caused anomalies and the ways to overcome them. Based on the analysis we recommend that in the substation must be installed power transformer and building new transmission lines are necessary in order to create ring/loop system instead of radial distribution system.
\end{abstract}

Keywords: Distributed system, SHP, Voltage level, Power quality.

\section{Introduction}

Over $90 \%$ of electricity in Albania is produced by hydropower plants. Hydropower plants are mainly located at north Albania and are built on Drin and Mat rivers with 1446 MW capacity [1]. Before building of small hydropower plants (SHPs), the hierarchal scheme of power system was radial means unidirectional the power flow. Due to this reason the power quality, mainly in the end of a radial line, is not at good and optimal conditions. It seems at low voltage levels of nodes in this part of Albania and significant transmission power losses. However, the voltage level at the radial line termination, in some cases, is below the allowed values [2]. In recent years, the interest of building small hydropower plants by private operators working in the field of energy production is increased. These resources are usually connected at the distributed power system. The power generated from SHPs is quite large. The use of hydropower reserves through construction of small hydropower plants, has not only the increase of the production of electricity, but also some other important advantages [1]. The presence of local generation in a distribution system will affect the distribution system. The distribution generation (DG) may alter the power flow in the distribution system, and the distribution system can no longer be considered as a system with unidirectional power flow [3]. Hence, the presence of the SHPs, will obviously impact in the strategy of local control of voltage level at the power distribution system operation [4]. On the other hand, in the distribution system for many years any investments have not been done by Distribution System Operator in Albania.

The aim of this article is to analyze the impact of small hydropower plants in power quality at the distribution system. Through the "Fluke 435 Power Quality Analyzer" instruments we have monitored for a period about 244 hours the power quality parameter at "Peshku" small hydropower plant. Specifically the parameter measured are: effective value of the phases voltage, the maximum value of the phase voltage, the minimum value of voltage, total harmonics distortion of voltage (THD, H1, H3, H5), the network frequency $(\mathrm{Hz})$, the voltage flicker: short term severity Pst ( measured over $10 \mathrm{~min}$ ) and long term severity Plt (measured over 2 hours), the asymmetry of voltage (\%). During this period the instrument was put in Logging Mode in order to read and registered all the above parameter required. From the data registered by instruments is found that the voltage level is unstable and fluctuation. Often, the new small hydropower plants, due to limited transmission lines capacities of distribution system, operate under their capacities. The mains reason of the problems appeared is the low capacity of transmission power line and the strategy of voltage control in power system. To overcome the anomalies in power system due to connected of small hydropower plants is necessary to investment at electrical distribution network and to increase the transmitted power of substations.

\section{The State of Small Hydropower Plants in Albania}

Over $90 \%$ of electricity in Albania is produced by hydropower plants. Hydropower plants are mainly located at north Albania and are built on Drin and Mat rivers with 1446 MW capacity. Also, in rural area are built many small hydropower plants (SHP) which produce energy during in winter and spring season. Mostly of them are built with canal deviation and their capacity depends by water flow and height. The power capacity of SHP was around $10 \%$ of total unit's generation in Albania in the end of 90' years. The capacity of each of them is between 100 to $800 \mathrm{~kW}$. After years 90', the most of SHP due to amortized and normal ageing was out of service. After 2000, started of privatization scheme in energy production and distributed fields. During the last years in Albania the interest of private investors concerning to small hydropower plants is increased, so around 80 concessionary contracts for construction of SHPs have been approved. The total capacity of SHPs is around $400 \mathrm{MW}$ with annual energy production of $1,827 \mathrm{GWh}$. The amount of investment of construction of SHP plants is about 289 million Euros. Nowadays, there are a number of private 


\section{International Journal of Science and Research (IJSR) \\ ISSN (Online): 2319-7064}

Index Copernicus Value (2013): 6.14 | Impact Factor (2014): 5.611

companies licensed to produce electricity and 23 of small hydropower plants are operated. In the Table I, for the period 2006 to 2014 is represented the energy annual production and installed capacity of small hydropower plants [5].

Table 1: SHPs Data in Albania

\begin{tabular}{|c|c|c|c|c|}
\hline \multirow{2}{*}{ Year } & \multicolumn{3}{|c|}{ Installed power } & Energy Annual production \\
\cline { 2 - 5 } & $k W$ & $\%$ & $M W h$ & $\%$ \\
\hline 2006 & 26,017 & 1.82 & 61,918 & 1.12 \\
\hline 2007 & 27,454 & 1.92 & 59,177 & 2.02 \\
\hline 2008 & 27,759 & 1.94 & 62,025 & 1.65 \\
\hline 2009 & 28,009 & 1.96 & 89,306 & 1.72 \\
\hline 2010 & 53,194 & 3.72 & 159,040 & 2.11 \\
\hline 2011 & 77,854 & 5.77 & 136,831 & 3.51 \\
\hline 2012 & 142,104 & 10.53 & 290,998 & 7.23 \\
\hline 2013 & 226,004 & 16.74 & 548,148 & 9.43 \\
\hline 2014 & 240,109 & 18.65 & 605,127 & 10.23 \\
\hline
\end{tabular}

Whereas in Fig. 1 is represented the energy annual production by small hydropower plants compare with public company hydropower plants. As shown by Fig.1 the energy production by small hydropower plants is increased in recent years.

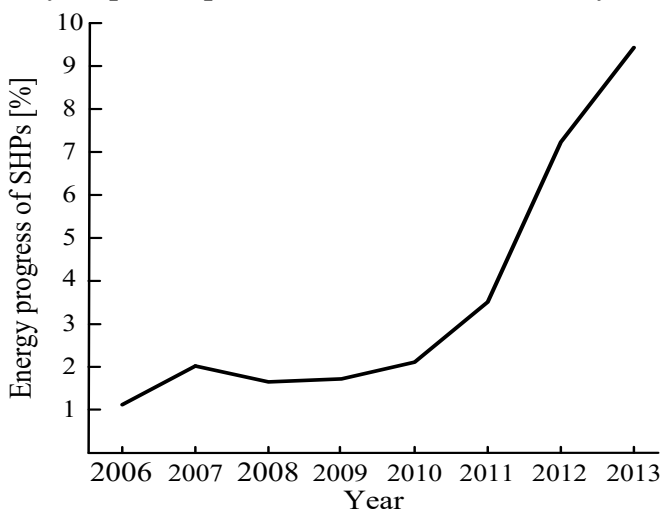

Figure 1: Energy progress of SHPs compared with the public company hydropower plants

\section{Power quality monitoring at Peshku SHP}

The electric network of regional power system Diber before "Peshku" small hydropower plant construction is shown in the Fig.2. As shown from Fig. 2, the Diber district is fed by a $110 \mathrm{kV}$ radial transmission lines from Burrel substation to Peshkopi. Downstream the transmission line Burrel Peshkopi are connected the substation which fed the Kuç, Bulqiza and Vojnik area. As shown by Fig.2 the distribution network of Diber area is radials. From the data given by Distribution System Operator the voltage level at the end of consumers often was under allowed level and transmission power losses are significantly. But, in recent years, as we says above in the Diber area are built some small hydropower plants.

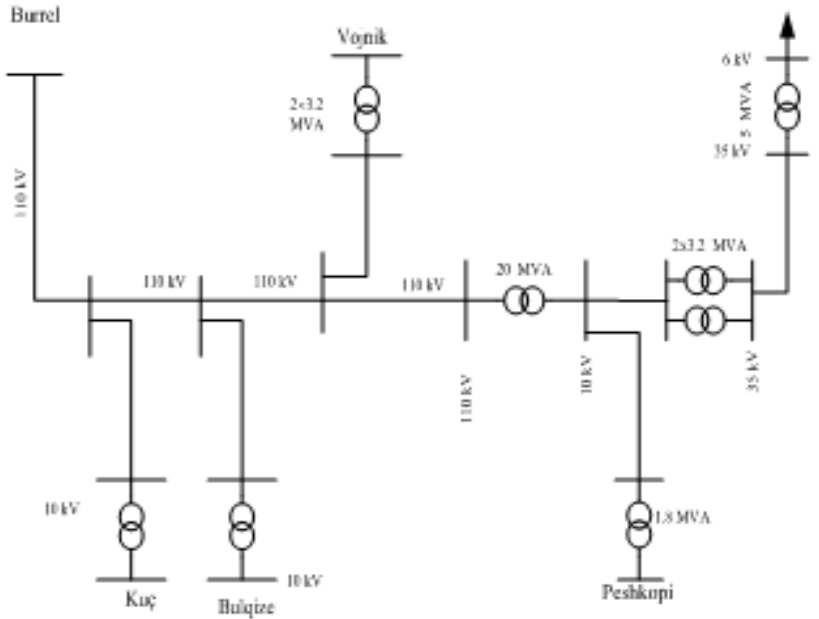

Figure 2: Schematic layout of regional power system Diber.

To monitor the impact of small hydropower plants at the power quality parameter of we have installed a measurement instrument at bars that Peshku small hydropower plant is connected at distributed network. Through the "Fluke 435 Power Quality Analyzer" instruments we have monitoring for a period about 244 hours the power quality parameter. Specifically the parameter measured are: effective value of voltage phases, the maximum (amplitude) value of the voltage phases, total harmonics distortion of voltage (THD, $\mathrm{H} 1, \mathrm{H} 3, \mathrm{H} 5)$, the network frequency $(\mathrm{Hz})$, the voltage flicker: short term severity Pst (measured over $10 \mathrm{~min}$ ) and long term severity Plt (measured over 2 hours), the asymmetry of voltage phases $(\%)$. During this period the instrument was stand in Logging Mode in order to reading and registering all the above parameter required. In Fig. 3 are shown the "Logger Events" during survey period. As shown from Fig. 3 the instrument has registered 10 events. The nature of the events is the voltage dip. From the instruments installed during the period survey are detected about ten events. As shown by details all the events have the same reason, voltage swell. The events results in effective voltage phase's values are below the limited allowed such as: $204 \mathrm{~V}, 2001 \mathrm{~V}, 187$ V, $151 \mathrm{~V}, 206 \mathrm{~V}, 205 \mathrm{~V}$ and $159 \mathrm{~V}$. During the period survey the power system shutdown, at date $03 / 24 / 15$ on $02 \mathrm{~h}: 10 \mathrm{~m}$ : $41 \mathrm{sec}$, duration about 30 minutes. All the "events" are appeared during the period time 07:00 AM until 11:00 AM.

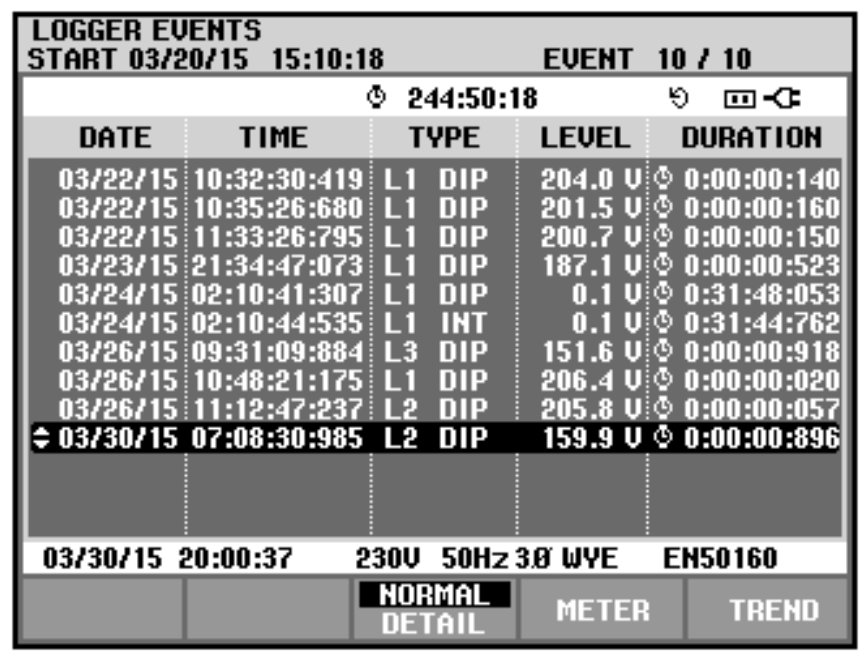

Figure 3: The logger events table screen. 


\section{International Journal of Science and Research (IJSR) \\ ISSN (Online): 2319-7064}

Index Copernicus Value (2013): 6.14 $\mid$ Impact Factor (2014): 5.611

\subsection{The data of RMS value of voltages phase during the period survey}

The effective voltage value read and registered by Fluke 435 instrument during the observation period are represented at Figs. 4, 5, 6. To emphasize the voltage fluctuation, at Fig. 4 is presented the data of effective voltages phases during all time survey otherwise at Fig. 5 and Fig. 6 are shown the data of voltage variations for 24 hours. As shown from above figures the value of voltage phases is not a constant value and in some cases the value of voltage phases is under of the limited allowed. As shown from fig. 6 during day - hours, the value of voltage phases is low than the allowed level. The reason of voltage variation is that the radial transmission line is calculated with limited capacity to support certain load. Whereas, in the area, in fact is a mining industry which means a considerably load. In rural electric power system, no investments have been performed by distribution system operator. This situation does not correspond to the increase of electricity consumption demands. Also, the regional power network has been put in trouble due to the connection of new energy resources.

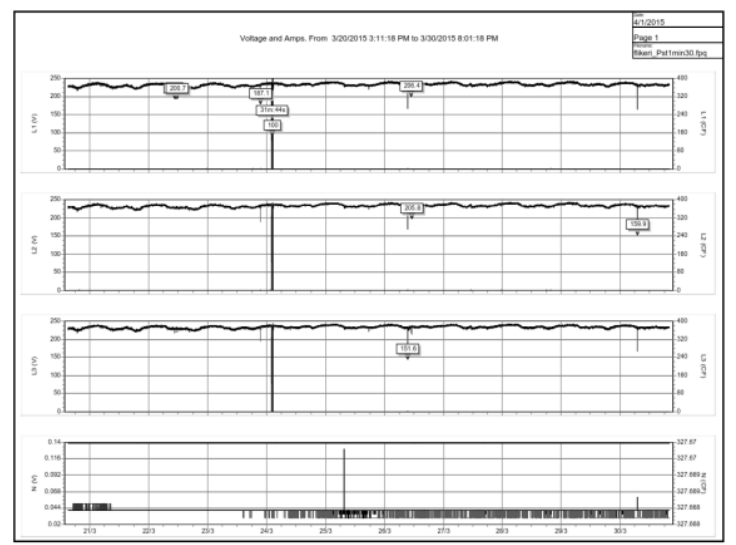

Figure 4: The data of effective value of voltage phases during period survey.

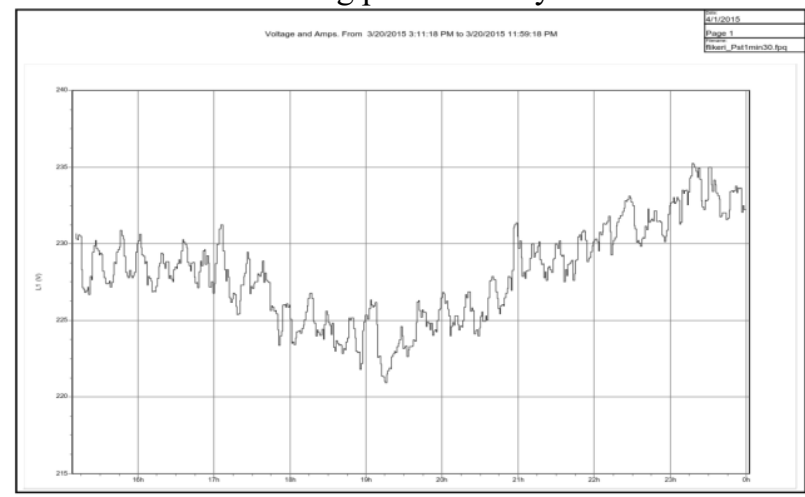

Figure 5: The data of effective value of voltage phases during period survey.

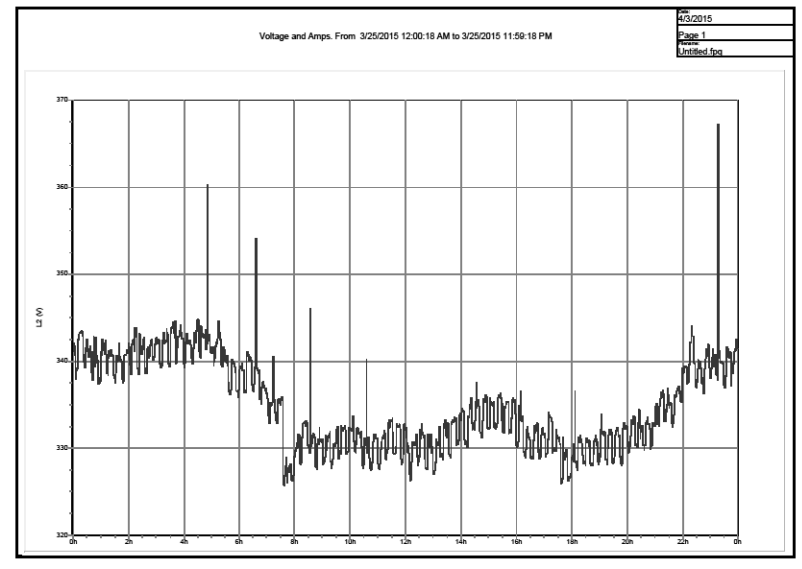

Figure 6: The data of effective value of voltage phases during period survey

3.2 The data of total harmonic distortion (thd) value during the period survey

In the power system accent the fundamental harmonic $(50 \mathrm{~Hz}$ frequency) contain a lot of different harmonics due to generation units or non linearity of loads as computer, semiconductor, battery of capacitors etc. The total harmonic distortion value as know is an important parameter to estimate the power quality. Base of international standards the value of TDH must be 1.4. In Fig. 7 is representing the coefficient of total distortion harmonic measurement during of period survey. As shown by fig. 8 this coefficients is upper than allowed value.

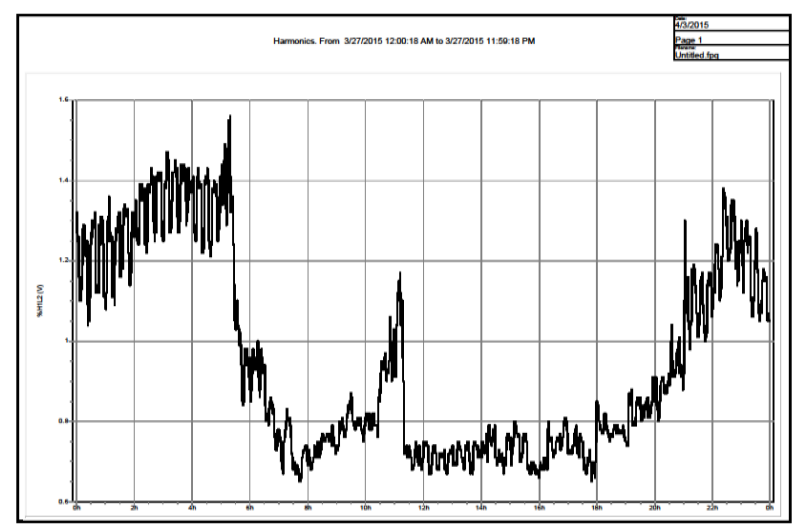

Figure 7: The data of total harmonic distortion during period survey

\subsection{The data of flicker during the period survey}

Voltage fluctuations are defined as cyclic variations in voltage with amplitude below $10 \%$ of the nominal value. Most of the connected equipment is not affected by voltage fluctuations, but these fluctuations may cause changes in the illumination intensity of light sources, known as flicker. Flicker may produce a very unpleasant visual sensation, leading to complaints from utility customers. The annoyance level depends on the type of lamp and amplitude, frequency and duration of the voltage fluctuations.

The small hydropower plants are usually with canal deviation and the energy injected in power system depends by climatic condition. Due to this reason energy injected by them in distribution system is not a constant value but changes to 


\section{International Journal of Science and Research (IJSR) \\ ISSN (Online): 2319-7064 \\ Index Copernicus Value (2013): 6.14 | Impact Factor (2014): 5.611}

cause the flicker phenomena. In Fig. 9 is representing the flicker coefficient measurement during of period survey. As shown by Fig. 8 this coefficients is upper than allowed value. This is caused by some reason. One of them is caused by the characteristic load. The load in the area which we have monitoring changed (the typically load in the area are: lift, conveyer and compressor).

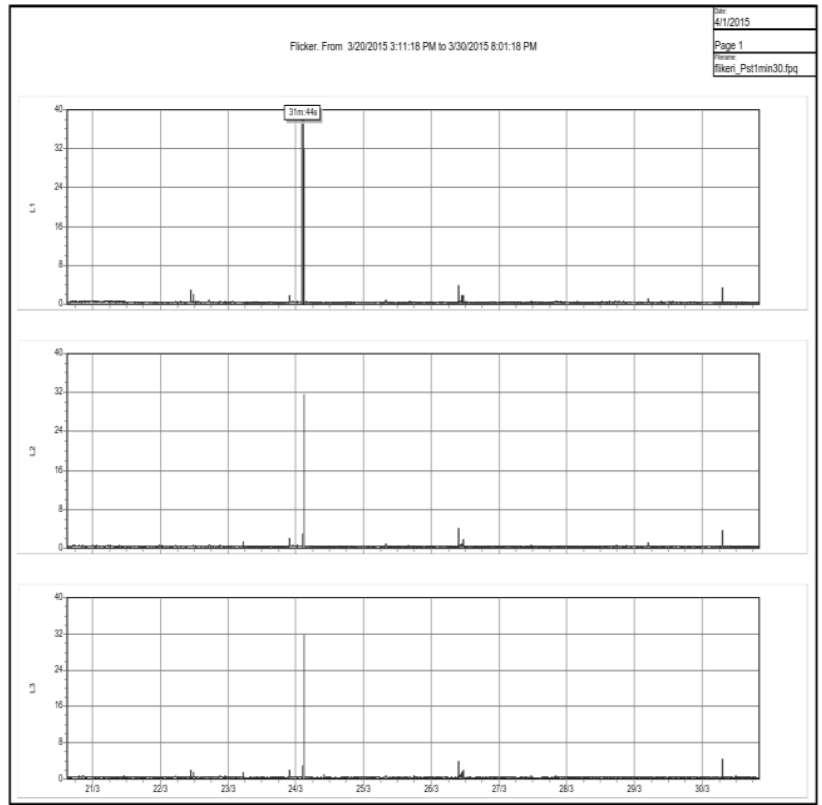

Figure 8: The data of flicker during 24 hour survey)

\section{Conclusion}

From the data reading and registered by "Fluke 435 -Three Phase Power Quality Analyzer' instrument during the period survey parameter of power system resulted that the level of voltage node is lower than allowed value i.e.: $204 \mathrm{~V}, 2001 \mathrm{~V}$, $187 \mathrm{~V}, 151 \mathrm{~V}, 206 \mathrm{~V}, 205 \mathrm{~V}, 159 \mathrm{~V}$.

During the period survey the power system shutdown, at date 03/24/15 on $02 \mathrm{~h}: 10 \mathrm{~m}$ : $41 \mathrm{sec}$, duration about 30 minutes. All the "events" are shown during the period time 07:00 AM until 11:00 AM. All the events have been done due low voltage level of power system. The effective voltage value reading and registered by Fluke 435 instrument during observation period results in voltage fluctuations. Frequency result at a constant value, $50 \mathrm{~Hz}$ during the monitoring time. The total voltage distortion (THDV) or the harmonic pollution parameters in several cases are over the limited allowed.

The distribution network of power system is radial configuration and amortized a large part of his. At rural electric power system, in recent years for many years any investments have not been done by Distribution System Operator. Also, these power networks have been put in trouble due to connected of new energy resources. In some cases, the capacities of the new hydropower station built exceed the capacity of power transformer installed at electrical distributed network.

In order to overcome the problems encountered by the connection of small hydropower plants to the power system is necessary to build the new transmission line in order to increase the transmitted capacity and to install power transformer On Load Tap Charger at the substation. To minimize the voltage fluctuation at the nodes when small hydropower plants are connected at power system is changed the system control of synchronous generators.

\section{References}

[1] M. Çelo, E. Zeqo, A. Ibrahimi, R., Bualoti “The Impact of Small HPP's in the Energy Balance of Albanian Power System", International Conference on Renewable Energies and Power Quality (ICREPQ'13) Bilbao (Spain), 20th to 22th March, 2013

[2] A. Bardhi, M. Braneshi, A. Pjetri, "Impact of distributed generation on power system: Case study", The 7 th International Scientific Conference on "Energy and Climate Change" Proceeding of Promitheas Conferences ISBN: 978-960-466-142-8 ISSN: 22417850-3 (204 page), page 115 - 120, (8 - 10) October, 2014/Athens

[3] T. Khoan, M. Vaziri, M.: "Effects of Dispersed Generation (DG) on Distribution Systems," IEEE in Power Engineering Society General Meeting, Sacramento, 16 June 2005,Vol 3,pp.2173-2178.

[4] A. Bardhi, M. Braneshi, M. Puka, TH. Koblara, "Problems encountered in Albanian power system by connection of new power generation units" The 8 th International Scientific Conference on "Energy and Climate Change" Proceeding of Promitheas Conferences, $(7-9)$ October, 2015/Athens

[5] KESH, 2006 - 2014, Annual Report.

\section{Author Profile}

Boris Cfarku was born in Tirana, Albania, in 1957. He received the Engineer degree in Electrical Engineering from the University of Tirana, Albania, in 1982, and the MSc degree in Power System from the same school in 2007. He is an Assistant teacher at Electrical Engineering Faculty of Polytechnic University of Tirana. His current research interests include electric machines, fault detection and localization, modeling and observation.

Nako Hobdari was born in Tirana, Albania, in 1946. He received the Engineer degree in Electrical Engineering from the Polytechnic University of Tirana, Albania, in 1968. He obtained the doctorate thesis on December 1984 in Electrical Engineering. He is an full time Profesor at Electrical Engineering Faculty of Polytechnic University of Tirana. His current research interests include insolation science, power system.

Astrit Bardhi was born in Tirana, Albania, in 1972. He received the Engineer degree in Electrical Engineering from the Polytechnic University of Tirana, Albania, in 2002, and the MSc degree in Power System and intelligent techniques from the same school in 2007. Hi obtained the doctorate thesis on December 2011 in Electrical Engineering. $\mathrm{He}$ is an Assistant teacher at Electrical Engineering Faculty of Polytechnic University of Tirana. His current research interests include electric machines, fault detection and localization, modeling and observation. 